\title{
STUDI KOMPARASI KADAR FLAVONOID TOTAL PADA BUNGA ROSELLA MERAH (Hibiscus sabdariffa L.) ASAL KABUPATEN LUWU UTARA PROVINSI SULAWESI SELATAN DAN KABUPATEN KEDIRI PROVINSI JAWA TIMUR
}

\author{
Saida I. Suradji ${ }^{1}$, Ahmad Najib, Aktsar Roskiana Ahmad \\ Fakultas Farmasi, Universitas Muslim Indonesia \\ 'Saida_suradji@yahoo.com
}

\begin{abstract}
Red Roselle (Hibiscus sabdariffa L.) is a medicinal plant used by the public as drugs. This plant is efficacious because one contains chemical constituents are flavonoids. Comparative Study of total Flavonoid content in red Roselle (Hibiscus sabdariffa L.) from North Luwu district of South Sulawesi province and the province of East Java Kediri district has done. The aim of study to determine of total flavonoid content in Kediri regency and district of North Luwu using a spectrophotometer. Extraction is done by maceration method using $96 \%$ ethanol. Phytochemical screening using the color reaction identification and determine content of Colorimetric method using UV-Vis spectrophotometry at the maximum wavelength of $417 \mathrm{~nm}$. Meanwhile the yield extract red Rosella from Kediri (sample I) $12.703 \%$ and red Rosella from north Luwu (sample II) $10.44 \%$. Test phytochemical to sample I and sample II positive containing Flavonoids. Test total Flavonoid content to sample I is $0.02816 \%$ and sample II is $0.2075 \%$.
\end{abstract}

Keywords: Flavonoid, red Roselle, Spectrophotometry UV-Vis

\section{PENDAHULUAN}

Keberadaan tanaman sebagai obat sudah dikenal sejak ribuan tahun lampau. Bukti sejarah ini terukir di helaian lontar, dinding-dinding candi dan kitab masa lalu. Resep diwariskan turun temurun yang tadinya hanya dikenal tertentu kemudian menyebar hingga masyarakat luas. Dunia mencatat tradisi herbal berkembang pesat di dunia timur. Modernisasi mentautkan tanaman obat dengan dunia farmasi perlahan-lahan keampuhannya diakui kalangan ilmiah. Walaupun begitu pemakaian tradisional tetap mendapat tempat. Dengan pengolahan yang benar khasiat tanaman obat tidak pernah akan berubah (Ismawan, 2010).

Obat tradisional indonesia telah lama dikenal dan dimanfaatkan oleh masyarakat dalam menjaga kesehatan dan mengobati penyakit yang diderita. Nenek moyang bangsa Indonesia telah mewariskan banyak obat-obatan yang telah teruji khasiatnya dan tetap lestari hingga saat ini dengan didukung oleh pembuktian ilmiah melalui uji praklinik dan uji klinik. Penggunaan obat tradisional di masyarakat memiliki kecenderungan untuk kembali ke alam dengan memanfaatkan berbagai tanaman obat, karena obat sintesis dirasakan terlalu mahal serta efek samping yang cukup besar (Wasito, 2011).

Beberapa penyakit kronis yang ditemui saat ini banyak yang disebabkan oleh radikal bebas yang berlebihan diantaranya kerusakan ginjal, diabetes, jantung koroner, hingga kanker. Radikal bebas dapat diredam dengan antioksidan. Antioksidan merupakan senyawa yang dapat menghambat reaksi oksidasi dengan mengikat radikal bebas dan molekul yang sangat reaktif (Winarsih, 2007). Rossella (Hibiscus sabdariffa L.) merupakan salah satu tanaman yang mengandung zat antioksidan (Suzery, 2010).

Rosela (Hibiscus sabdarifa L.) termasuk famili Malvaceae yang merupakan tanaman tropis yang banyak tumbuh di Indonesia. Kelopak bunganya biasa digunakan pada pengobatan tradisional, seperti pengobatan penyakit batuk, gangguan pencernaan, menurunkan tekanan darah, merangsang gerak peristaltik usus serta berpengaruh terhadap fungsi diuretik (Suzery,,2010), bagian daun, bunga serta akar rosela memiliki khasiat sebagai diuretik, ekspektoran, mencegah vertigo, sedatif, emolien, anti-piretik, anti-spasmodik, antiskorbat, laksatif, uterorelaksan, melancarkan gerak peristaltik usus dan anti-reumatik (Duke, 2002).

Kelopak bunga Rosella (Hibiscus sabdariffa L.) memiliki kandungan flavonoid (Sonia dkk, 2007; Mardiah, 2009). Senyawa flavonoid diduga sangat bermanfaat dalam makanan, karena berupa senyawa fenolik, senyawa ini yang bersifat antioksidan kuat (Heinrich et al., 2009).

Senyawa flavonoid juga mempunyai berbagai fungsi penting untuk kesehatan, antara lain dalam menurunkan risiko serangan penyakit kardiovaskuler, tekanan darah, aterosklerosis, dan sebagai antioksidan (Hodgson et al., 2006). Oleh karena itu makanan yang kaya flavanoid dianggap penting untuk mengobati penyakit-penyakit, seperti 
kanker dan penyakit jantung (yang dapat memburuk akibat oksidasi lipoprotein densitas-rendah) (Heinrich et al., 2009)

Kadar antioksidan yang terkandung dalam kelopak kering Rosella jauh lebih tinggi dibandingkan dengan tanaman kumis kucing. Kadar antioksidan yang tinggi pada kelopak Rosella dapat menghambat radikal bebas. (Hasibuan, 2010).

Pentingnya manfaat flavonoid sebagai antioksidan, maka penetapan kadar flavonoid total pada bunga Rosella Merah (Hibiscus sabdariffa L.) dengan perbedaan tempat tumbuh perlu dilakukan, sehingga pemanfaatan Rosella Merah (Hibiscus sabdariffa L.) lebih dimaksimalkan dalam alternatif pengobatan herbal berbagai macam penyakit. Oleh karena itu, pada penelitian ini peneliti ingin membandingkan kadar flavonoid total pada bunga Rosella Merah (Hibiscus sabdariffa L.) pada daerah dengan iklim yang berbeda yakni di daerah kabupaten Luwu Utara Provinsi Sulawesi Selatan dan kabupaten Kediri Provinsi Jawa Timur. Alasan pemilihan kedua daerah tersebut adalah karena berdasarkan letak geografis dari kedua daerah tersebut, dimana kabupaten Luwu Utara mewakili daerah dengan iklim yang sangat basah dan kabupaten kediri mewakili daerah dengan iklim kering, selain itu juga kedua daerah ini memiliki perbedaan yaitu kabupaten luwu utara merupakan daerah dataran tinggi sedangkan kabupaten kediri merupakan daerah dataran rendah.

\section{METODE PENELITIAN \\ A. Pengambilan dan Pengolahan Sampel}

Sampel Bunga Rosella Merah (Hibiscus sabdariffa L.) diambil dari dua daerah yaitu dari Masamba kabupaten Luwu Utara Provinsi Sulawesi Selatan dan kecamatan Semen kabupaten Kediri provinsi Jawa Timur. Sampel kemudian dibersihkan dari kotoran yang melekat dengan menggunakan air mengalir lalu dikeringkan dengan cara dianginanginkan. Setelah kering, sampel dipotong-potong kecil, kemudian diserbukkan dan diekstraksi dengan metode maserasi.

\section{B. Pembuatan Ekstrak}

Ditimbang masing 1000 gram serbuk

Bunga Rosella Merah (Hibiscus sabdariffa L.) asal Kediri dan 80 gram asal Luwu Utara, kemudian dimasukan serbuk Bunga Rosella Merah yang akan disari kedalam bejana maserasi. Dituang secara perlahan etanol $96 \%$ sebanyak 1,5 L kedalam bejana maserasi yang berisi serbuk Bunga Rosella Merah. Kemudian biarkan cairan penyari merendam serbuk simplisia selama 3 hari sesekali dilakukan pengadukkan, dilakukan remaserasi sebanya 1 kali dengan pelarut 1,5 L. Selanjutnya disaring ke dalam wadah baru sehingga diperoleh ekstrak cair. Ekstrak cair diuapkan hingga diperoleh ekstrak kental (Suzery, 2010).

\section{Analisis Kualitatif}

$10 \mathrm{mg}$ ekstrak ditambahkan $4 \mathrm{~mL}$ etanol 95\% hingga ekstrak larut (Depkes RI, 1995):

1. Dua ml larutan uji ditambahkan 0,5 gram serbuk seng, kemudian ditambahkan $2 \mathrm{~mL} \mathrm{HCl}$ 2N, didiamkan 1 menit. Kemudian ditambahkan 10 tetes $\mathrm{HCl}$ pekat $\mathrm{P}$. Dikocok perlahan, kemudian didiamkan 2-5 menit. Terbentuk warna merah intensif (positif flavonoid).

2. Dua $\mathrm{mL}$ larutan uji ditambahkan 0,1 gram serbuk magnesium. Kemudian ditambahkan 10 tetes $\mathrm{HCl}$ pekat P. Dikocok perlahan.Terbentuk warna merah jingga hingga merah ungu (positif flavonoid) atau kuning jingga (flavon, kalkon, auron).

\section{Analisis Kuantitatif}

1. Pembuatan pereaksi $\mathrm{CH}_{3} \mathrm{COOK} 1 \mathrm{M}$

Ditimbang sebanyak 0,982 gram CH3COOK kemudian dilarutkan dengan akuadest steril hingga $10 \mathrm{~mL}$.

\section{Pembuatan pereaksi $\mathrm{AlCl}_{3} 10 \%$}

Ditimbang sebanyak 1,8 gram $\mathrm{AlCl}_{3} \quad 10 \%$ dilarutkan dengan aquadest steril hingga $10 \mathrm{~mL}$.

\section{Pembuatan kurva baku}

Ditimbang $10 \mathrm{mg}$ rutin dilarutkan dalam metanol dan kemudian diencerkan menjadi 10, 15, 20, 25 dan 30 dan $\mu \mathrm{g} / \mathrm{mL}$. Larutan standar yang diencerkan (1 $\mathrm{mL})$, secara terpisah dicampur dengan $3 \mathrm{~mL}$ metanol, 0,2 $\mathrm{mL}$ aluminium klorida $10 \%, 0,2 \mathrm{~mL}$ kalium asetat $1 \mathrm{M}$ dan 5,6 mL air suling. Setelah inkubasi pada suhu kamar selama 30 menit, absorbansi dari campuran reaksi diukur di $417 \mathrm{~nm}$ dengan spektrofotometer UV-1601 Shimadzu (Kyoto, Japan). Jumlah 10\% alumunium klorida di gantikan oleh jumlah yang sama dari air suling dalam blank (Chang et al, 2002).

\section{Pembuatan larutan ekstrak bunga Rosella} Merah (Hibiscus sabdariffa L.)

Larutan ekstrak Rosella Merah (Hibiscus sabdariffa L.) dibuat dengan cara menimbang 100 mg dilarutkan hingga $100 \mathrm{~mL}$ dengan metanol.

\section{Penentuan kadar flavonoid total pada bunga}

Rosella Merah (Hibiscus sabdariffa L.) Kadungan flavonoid total ditentukan menurut prosedur Chang et al, (2002) yang divalidasi oleh Mujahid (2011) menggunakan rutin sebagai 
pembanding standar baik ekstrak etanol bunga Rosella Merah dan rutin (100 mg) di larutkan kedalam $100 \mathrm{~mL}$ metanol. Sesudah itu, larutan diencerkan untuk menghasilkan rangkaian konsentrasi (10, 15, 20, 25 dan $30 \mathrm{mg} / \mathrm{mL})$. Larutan uji (1 mL) ditambahkan dengan $3 \mathrm{~mL}$ metanol, $0,2 \mathrm{~mL} \mathrm{AlCl}_{3}$ 10\%, 0,2 mL Kalium Asetat $1 \mathrm{M}$ dan 5,6 mL air suling, dan di inkubasi selama 30 menit.
Selanjutnya, absorban diukur pada panjang gelombang $417 \mathrm{~nm}$, dan air suling dengan $\mathrm{AlCl}_{3}$ digunakan sebagai blanko. Kandungan flavonoid total dinyatakan dalam gram eukivalen rutin (RE) dar masing-masing 100 gram ekstrak etanol bunga Rosella Merah dari berat kering (Nugroho et al, 2013).

\section{HASIL DAN PEMBAHASAN}

\section{A. Hasil Penelitian}

Tabel 1. Hasil ekstraksi rosella merah (Hibiscus sabdariffa L.)

\begin{tabular}{ccccccc}
\hline No. & $\begin{array}{c}\text { Jenis } \\
\text { Pelarut }\end{array}$ & Sampel & $\begin{array}{c}\text { Jumlah } \\
\text { Pelarut }(\mathbf{m L})\end{array}$ & $\begin{array}{c}\text { Berat Sampel } \\
(\mathbf{g})\end{array}$ & $\begin{array}{c}\text { Hasil } \\
\text { Ekstrak (g) }\end{array}$ & $\begin{array}{c}\text { Rendamen } \\
\text { Ekstrak (\%) }\end{array}$ \\
\hline 1 & Etanol 96\% & Kdiri & 3000 & 1000 & 127,03 & 12,703 \\
2 & Etanol 96\% & Luwu Utara & 3000 & 80 & 8,353 & 10,44 \\
\hline
\end{tabular}

Tabel 2. Tabel analisis kualitatif ekstraksi rosella merah (Hibiscus sabdariffa L.)

\begin{tabular}{cc}
\hline $\begin{array}{c}\text { Ekstrak Bunga Rosella } \\
\text { Merah }\end{array}$ & $\begin{array}{c}\text { Kandungan Kimia } \\
\text { Flavonoid }\end{array}$ \\
\hline Luwu Utara & + \\
Kediri & + \\
\hline Keterangan: $(+)$ & $=$ positif, \\
$(-)$ & $=$ negatif
\end{tabular}

Tabel 3. Hasil pengukuran absorbansi larutan standar Rutin pada panjang gelombang $417 \mathrm{~nm}$.

\begin{tabular}{cc}
\hline $\begin{array}{c}\text { Konsentrasi } \\
(\mathbf{p p m})\end{array}$ & Absorbansi \\
\hline 10 & 0,101 \\
15 & 0,118 \\
20 & 0,126 \\
25 & 0,141 \\
30 & 0,153 \\
\hline
\end{tabular}

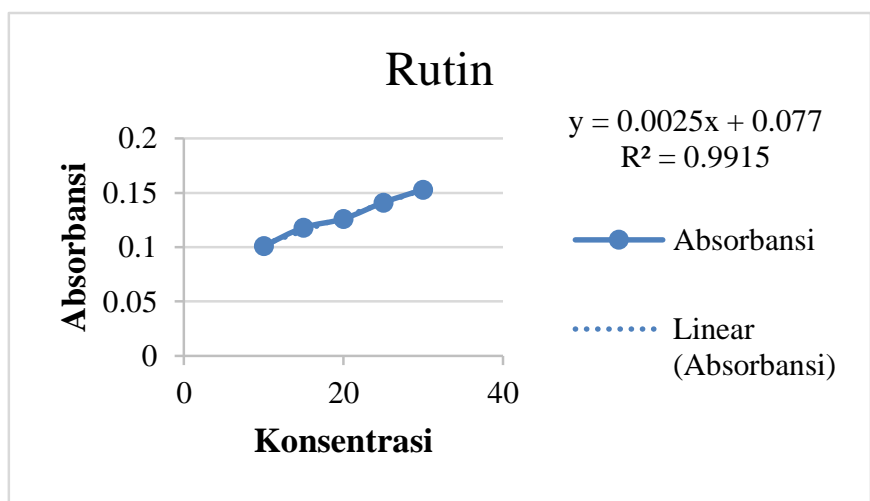

Gambar 1. Kurva kalibrasi rutin pada panjang gelombang $417 \mathrm{~nm}$

Tabel 4. Nilai Absorbansi sampel ekstrak etanol bunga Rosella Merah (Hibiscus sabdariffa L.) asal kabupaten Kediri dan Luwu Utara

\begin{tabular}{ccc}
\hline Replikasi & $\begin{array}{c}\text { Absorbansi } \\
\text { Ekstrak Rosella } \\
\text { Mrah (Kediri) }\end{array}$ & $\begin{array}{c}\text { Absorbansi } \\
\text { Ekstrak Rosella } \\
\text { Merah (Luwu } \\
\text { Utara) }\end{array}$ \\
\hline 1 & 0,0813 & 0,1185 \\
2 & 0,0824 & 0,1198 \\
3 & 0,0842 & 0,1172 \\
\hline
\end{tabular}


Tabel 5. Hasil penetapan kadar flavonoid total \% (b/b) pada ekstrak etanol bunga Rosella Merah (Hibiscus sabdariffa $\mathrm{L}$.)

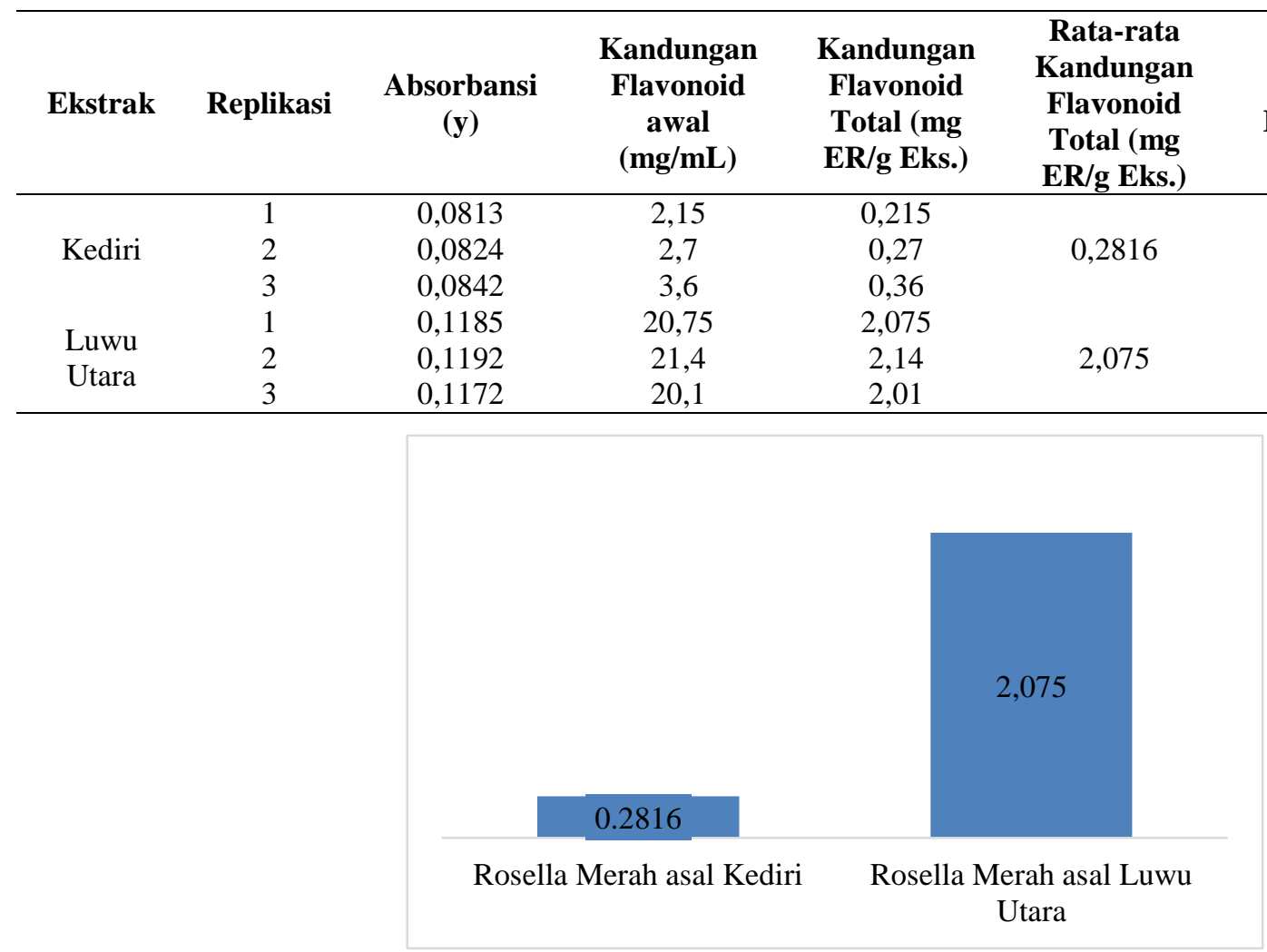

Gambar 2. Presentase kadar flavonoid total ekstrak etanol bunga Rosella Merah (Hibiscus sabdariffa L.) asal kabupaten Kediri dan Luwu Utara

\section{B. Pembahasan}

Rosela merupakan salah satu tanaman yang banyak tumbuh Indonesia dengan yang merupakan suku malvaceae dengan nama latin Hibiscus sabdariffa L. Terdapat beberapa jenis Rosela yaitu Rosela merah dan Rosella Ungu. Tanaman ini pun banyak di budi dayakan oleh masyarakat dan digunakan sebagai tanaman obat.

Salah satu kandungan kimia pada bunga Rosela yaitu Flavonoid. Flavonoid adalah suatu kelompok senyawa fenol yang terbesar ditemukan dialam.Senyawa-senyawa ini merupakan zat warna merah, ungu, biru, dan kuning yang ditemukan dalam tumbuh-tumbuhan. Flavonoid mempunyai kerangka dasar karbon yang terdiri dari 15 atom karbon, dimana dua cincin benzene terikat pada suatu rantai propane sehingga membentuk suatu susunan $\mathrm{C}_{6}-\mathrm{C}_{3}-$ C6. Susunan ini dapat menghasilkan tiga jenis struktur, yakni 1,3-diarilpropan atau flavonoid, 1,2diarilpropan atau isoflavonoid, dan 1,1-diarilpropan atau neoflavonoid (Markham, 1988).

Tujuan penelitian ini adalah untuk membandingkan kadar flavonoid total pada ekstrak bunga Rosela Merah anatar kabupaten Luwu Utara dan kabupaten Kediri (Hibiscus sabdariffa L.) yang berpotensi sebagai sumber bahan obat.

Bunga rosella Merah (Hibiscus sabdariffa L.) yang diambil pada kedua daerah yaitu pada bulan Oktober 2013 yang berasal dari desa Puhsarang Kecamatan Semen kabupaten Kediri dan Masamba kabupaten Luwu Utara. Tumbuhan utuh yang masih segar kemudian dideterminasi di Laboratorium Farmakognosi-Fitokimia Fakultas Farmasi Universitas Muslim Indonesia untuk memastikan kebenaran tanaman yang digunakan. Hasil identifikasi tanaman menunjukkan bahwa sampel merupakan jenis tanaman rosella Merah (Hibiscus sabdariffa L.) dari famili Malvaceae.

Sampel yang digunakan yaitu kelopak bunga Rosela Merah yang kemudian dibersihkan dan dikeringkan dengan cara diangin-anginkan selama \pm 2 minggu.

Untuk memperoleh senyawa kimia dari suatu tanaman maka perlu dilakukan ekstraksi. Pemilihan pelarut didasarkan pada kelarutan komponen terhadap komponen lain dalam campuran. Kelarutan suatu komponen tergantung pada derajat polaritas pelarut 
yang ditentukan oleh konstanta dielektrikum. Senyawa yang bersifat polar hanya dapat larut dalam pelarut polar, dan semi polar begitu juga sebaliknya senyawa non polar hanya dapat larut dalam pelarut non polar dan semi polar sebagaimana prinsip like dissolves like. Metode ekstraksi yang digunakan adalah maserasi, dimana kedua sampel yang berasal dari dua daerah ini diserbukkan terlebih dahulu sebelum diekstraksi agar senyawa kimia yang diinginkan mudah diperoleh. Simplisia dalam bentuk serbuk lebih mudah tersari karena luas kontak antara permukaan jaringan sel dengan pelarut lebih besar (Depkes RI, 2008).

Dalam penelitian ini pelarut yang digunakan untuk mengekstrekasi senyawa flavonoid adalah etanol. Senyawa flavonoid umumnya bersifat polar dan dapat diekstraksi dengan menggunakan etanol (polar) (Harborne, 1987).

Metode maserasi dipilih karena metode ini sederhana, murah dan mudah dilakukan. Serbuk kelopak bunga Rosella merah yang berasal dari kedua daerah yaitu kabupaten Kediri sebanyak $1 \mathrm{~kg}$ dan Kabupaten 70 gram, masing-masing dilarutkan dengan etanol $96 \%$ sebanyak 1,5 L untuk sampel yang berasal dari Luwu Utara dan diremaserasi sebanyak 1 kali dengan jumlah pelarut 1,5 L. Sedangkan untuk sampel yang berasal dari Kediri dilarutkan dengan pelarut sebanyak 2 liter dan diremaserasi sebanyak 1 kali dengan 1,5 L pelarut.

Hasil ekstrak yang diperoleh dari kedua daerah yaitu berwarna merah untuk ekstrak yang berasal dari Kediri yaitu 127,03 gram sedangkan yang bersal dari Luwu Utara sebesar 8,353 gram.

Hasil dari rendamen ekstrak bunga Rosella Merah yang berasal dari Kediri yaitu 12,703\% dan rendamen bunga ekstrak Rosella Merah asal Luwu Utara sebesar 10,44\%.

Hasil skrining menunjukkan bahwa ekstrak etanol bunga Rosella Merah memang positif mengandung Flavonoid.

Analisis Flavanoid total dilakukan dengan metode kolorimetri Chang et al (2002). Tahapan pembuatan larutan standar, yakni dengan menggunakan larutan standar flavonoid rutin. Digunakan larutan standar rutin, karena flavonoid paling sering ditemukan pada tumbuhan dalam bentuk glikosida seperti kuersetin 3-rutinosida atau senyawa rutin (Nugroho et al, 2013).

Pada pengukuran senyawa flavonoid total pada larutan ekstrak ditambahkan $\mathrm{AlCl}_{3}$ sehingga terjadi pembentukan kompleks antara flavanoid dan $\mathrm{AlCl}_{3}$ yang berwarna kuning serta kalium asetat dan aquabides didapat larutan ekstrak sampel berwarna kuning konstan, didiamkan selama 30 menit dalam keadaan gelap pada suhu kamar dan diukur absorbansi larutan pada serapan maksimum $417 \mathrm{~nm}$ dengan spektrofotometri UV-Vis. Senyawa-senyawa ini merupakan zat warna merah, ungu dan biru sehingga berfungsi sebagai zat warna kuning yang ditemukan dalam tumbuh-tumbuhan.

Hasil penelitian ini menunjukkan bahwa kandungan senyawa flavonoid pada ekstrak etanol bunga Rosella Merah (Hibiscus sabdariffa L.) asal kabupaten Luwu Utara adalah $0,2075 \%$ yang menunjukkan relatif lebih banyak daripada ekstrak bunga Rosella Merah (Hibiscus sabdariffa L.) asal kabupaten Kediri yang hanya mengandung 0,02816 $\%$.

Kadar Flavonoid Total pada bunga Rosella Merah (Hibiscus sabdariffa L.) yang berasal dari Luwu Utara lebih tinggi, hal ini dikarenakan oleh beberapa faktor yang dapat mempengaruhi seperti ketinggian, yang mana daerah Luwu Utara merupakan daerah ketinggian sedangkan daerah Kediri merupakan dataran rendah. Daerah dataran tinggi atau pegunungan memiliki curah hujan yang lebih tinggi dengan suhu yang lebih rendah dan kecepatan penguraian bahan organik dan pelapukan mineral berjalan lebih lambat begitu pula sebaliknya pada daerah dataran rendah penguraian bahan organik dan pelapukan mineral berjalan lebih cepat. Oleh karena itu di daerah ketinggian atau pegunungan tanahnya relatif lebih subur, kaya bahan organik dan unsur hara dibandingkan dengan tanah di daerah dataran rendah. Tinggi tempat berpengaruh terhadap suhu udara dan intensitas cahaya. Suhu dan intensitas cahaya akan semakin kecil dengan semakin tingginya tempat tumbuh Cahaya berpengaruh langsung pada ketersediaan makanan. Klorofil dibentuk dari hasil fotosintesis dan berpengaruh secara langsung terhadap pertumbuhan setiap organ atau terhadap keseluruhan tumbuhan (Susanti et al, 2012).

Ditinjau dari segi tanah, tanah pada daerah kediri merupakan jenis tanah aluvial, tanah ini memiliki tekstur yang cenderung kasar dengan kandungan senyawa organik dan unsur hara yang lebih rendah dibandingkan dengan tanah dengan tekstur halus tanah pada daerah Luwu Utara merupakan tanah mediteran yang merupakan tanah kapur dan batuan sedimen dengan tekstur halus. Tanah pada daerah pegunungan relatif lebih subur, kaya bahan organik dan unsur hara. Pada umumnya Rosella sendiri dapat tumbuh pada semua jenis tanah selama tanah tersebut kaya akan humus, gembur dan memiliki drainase yang baik (Widyanto dan Nelistya, 2009). Perbedaan tanah pada kedua daerah ini menyebabkan perbedaan kandungan Flavonoid total pada bunga Rosella Merah yang tumbuh pada daerah tersebut.

Daerah Luwu Utara merupakan daerah yang paling potensial dengan kandungan Flavonoid total paling besar sehingga perlu dibudidayakan tanaman 
Rosella Merah (Hibiscus sabdariffa L.) pada daerah tersebut sebagai sumber bahan baku obat baru.

Senyawa Flavonoid dalam bidang Farmasi berfungsi sebagai antioksidan kuat (Heinrich et al, 2009; ciz et al, 2010), sebagai antimikroba, antibakteri, antivirus, antiinflamasi, antimutagenik, antikanker, antiplatelet dan lain- lain (Setyawan dan Darusman, 2008), Flavonoid juga berfungsi untuk Hipertensi, aterosklerosis (Hodsgon et al, 2006).

\section{KESIMPULAN}

Dari hasil penelitian dilakukan, dapat disimpulkan bahwa kadar flavonoid total untuk ekstrak bunga Rosella Merah asal kediri yaitu 0,2816 $\mathrm{mg} \mathrm{RE} / \mathrm{g}$ dengan persentase 0,02816\% dan untuk ekstrak bunga Rosella Merah asal Luwu Utara yaitu 2,075 $\mathrm{mg} \mathrm{RE} / \mathrm{g}$ dengan persentase $0,207 \%$.

\section{DAFTAR PUSTAKA}

Agoes, G., 2007. Teknologi Bahan Alam. Institut Teknologi Bandung, Bandung.

Ansel, H. C., 1989. Pengantar Bentuk Sediaan Farmasi, Edisi Ke-4. UI-Press, Jakarta.

Blunden, G., Ali, H. B., dan Wabel, A. N. 2005. Phytochemical, Pharmacologicalan Toxicological Aspect of Hibiscus sabdariffa L. Phytoter Res 19.

Chang, CC., Yang, M. H., Wen, H. M., and Chern J. C., 2002. Estimation of Total Flavonoid Content in Propolis by Two Complementary Colorimetric Methods. Journal Food Drug Anal.

Christian, GD, 1986. Analytical Chemistry, Ed. 4. J. Wiley: New York.

Ciz, M., Hana Č., Petko D., Maria, K., Anton, S., Antonin, L., 2010. Different methods for control and comparison of the antioxidant properties of vegetables, Food Control

Departemen Kesehatan Republik Indonesia. (1995). Materia Medika IndonesiaJilid VI. Jakarta:

Direktorat Jenderal Pengawasan Obat dan Makanan.1979. Farmakope Indonesia. Departemen Kesehatan RI, Jakarta.

Direktorat Jendral Pengawasan Obat dan Makanan.1987. Analisis Obat Tradisional, Jilid I. Departemen Kesehatan RI, Jakarta.

Direktorat Jenderal Pengawasan Obat dan Makanan, 1986.Sediaan Galenik. Departemen Kesehatan RI: Jakarta.

Esselen, W.B. dan Sammy, G.M. (1975). Roselle: A Natural Red Colorant for Food. Food Product and Development 7: 80-82

Duke, J.A, duCellier, J., Mary J.B., dan K. Duke, P. 2002. Handbook of Medicinal Herbs,
Second Edition. United States of America: CRC Press LLC.

Fessenden, dkk., 1986. Kimia Organik Edisi III. Glora Aksara Pratama: Jakarta.

Fitria. 2007. Isolasi dan Identifikasi Senyawa Flavonoid Dalam Daun Paliasa. Universitas Hasanuddin: Makassar.

Hasibuan, D., 2010. Pengaruh jenis dan konsentrasi zat penstabil terhadap mutu Selai Rosella. (Skripsi). Medan: Universitas Sumatera Utara.

Heinrich, M., Barnes, J., Gibbons, S., 2009. Farmakognosi dan Fitoterapi.Terjemahan Winny R. Syarief, dkk. EGC: Jakarta

Hodgson, J. M., and Kevin D. C., 2006, Review Dietary flavonoids: effects on endothelial function and blood pressure, J Sci Food Agric

Hutapea, R., 2005. Sehat dan Ceria DiusiaSenja. Penerbit: Rineka Cipta. Jakarta.

Ismawan, Bambang, 2010. Herbal Indonesia Berkhasiat, Vol 8. PT Trubus Swadaya. Bogor.

Khopkhar, S. M., 2008. Konsep Dasar Kimia Analitik. Jakarta: UI Press.

Kristina, dkk., (2008). Perilaku Pengobatan Sendiri yang Rasional pada Masyarakat Kecamatan Depok dan Cangkringan Kabupaten Sleman. Jakarta: Majalah Farmasi Indonesia.

Mahadevan, N., Shivali and Kamboj, P., 2009. Natural Product Radiance. Hibiscus sabdariffa Linn.-An overview. Vol. 8(1).

Mardiah, dkk., 2009. Budi Daya dan Pengolahan Rosella Si Merah Segudang Manfaat. Agro Media Pustaka, Jakarta.

Markham, K.R., 1988. Cara Mengidentifikasi Flavonoid. Terjemahan K. radnawinata. Penerbit ITB: Bandung.

Mujahid, R. 2011. Pemilihan metode analisis flavonoid secara spektroskopi UV-Vis serta penerapannya pada seledri (Apium graviolens L.) murbei (Morus alba L.) patikan kebo (Euphorbia hirta L.) dan jeruk nipis (Citrus aurantifolia). Jogjakarta, Indonesia: Faculty of Pharmacy Universitas Gadjah Mada, MSc thesis.

Mulja, M dan Suharman, A., 1995. Instrumental Analisis. Airlangga Universitas Press. Surabaya.

Nugroho, A. N., Malik, A., Pramono, S., 2013.. Total phenolic and flavonoid contents, and in vitro antihypertension activity of purified extract of Indonesian cashew leaves (Anacardium occidentale L.). International Food Research Journal 20(1) 
Robinson, T., 1995. Kandungan Organik Tumbuhan Tinggi. Terjemahan Kosasih Padmawinata. ITB: Bandung

Sastrohamidjojo, H., 2007. Kromatografi. Liberty, Yogyakarta.

Steenis, V., 2005. Flora "Untuk Sekolah di Indonesia". Penerbit Pradnya Paramita. Jakarta.

Sudjadi, H. S., 1987. Metode Pemisahan. Kanisius: Jakarta.

Suzery, M., Lestari L., Cahyono, B., 2010 Jumal Sains \& Matematika (JSM) Penentuan total antosianin dari kelopak bunga Rosela (Hibiscus sabdariffa l) dengan metode maserasi dan sokshletasi, Volume18,No.1.(http://ejournal.undip.ac.id/i ndex.php/sm/article/download/3 116/2796) (diakses tanggal 4 september, 2013)

The Integrated Taxonomic Information System. 2009. (Online)(http://www.itis.gov/servlet/singleR $\mathrm{pt} /$ singlRpt) (diakses 24September 2013).

Voight, R., 1995. Buku Pelajaran Teknologi Farmasi. Gadjah Mada University Press, Yogyakarta.

Wasito, H., 2011. Obat Tradisional Kekayaan IndonesiaEdisi pertama. Graha ilmu, Yogyakarta.

Widyanto, P.S., dan A. Nelistya., 2008. Rosella. Aneka Olahan, Khasiat dan Ramuan. Penebar Swadaya, Jakarta.

Wildah, Dj. 2001. Isolasi dan Identifikasi Flavonoid Pada Daun Kemuning [Skripsi]. Jurusan Farmasi Fakultas MIPA. Universitas Hasanuddin: Makassar.

Winarsi, Hery. 2007. Antioksidan Alami dan Radikal bebas. Kanisius, Yogyakarta.

Yulianto, D., 2009. Inhibisi Xantin Oksidase Secara In Vitro oleh Ekstrak Rosela (Hibiscus sabdariffa) dan Ciplukan (Physalis angulata) Bogor: Departemen Kimia Institut Pertanian Bogor 